\title{
Three new species of gall midge (Diptera: Cecidomyiidae) from Maharashtra, India
}

\author{
S.S. Bhalerao ${ }^{1}$, T.H. Shaikh ${ }^{2}$ \& V.D. Deshpande ${ }^{3}$ \\ ${ }^{1}$ Department of Zoology, Bahirji Smarak College, Basmatnagar, Hingoli, Maharashtra 431215, India \\ ${ }^{2}$ Shahu College, Bhokar, Nanded, Maharashtra 431801, India \\ ${ }^{3}$ Post Graduate Department of Zoology, N.E.S. Science College, Nanded, Maharashtra 431605, India
}

Date of publication 26 April 2009 ISSN 0974-7907 (online) | 0974-7893 (print)

Editor: R.M. Sharma

\section{Manuscript details:}

Ms \# 01573

Received 01 June 2006

Final revised received 20 November 2008

Finally accepted 23 January 2009

Citation: Bhalerao, S.S., T.H. Shaikh \& V.D Deshpande (2009). Three new species of gall midge (Diptera: Cecidomyiidae) from Maharashtra, India. Journal of Threatened Taxa 1(4): 226-229

Copyright: () S.S. Bhalerao, T.H. Shaikh \& V.D. Deshpande 2009. Creative Commons Attribution 3.0 Unported License. JoTT allows unrestricted use of this article in any medium for non-profit purposes, reproduction and distribution by providing adequate credit to the authors and the source of publication.

Author Details: S.S.BHALERAO presently works on a minor project "Study of Gall and Gall Midge from Nanded District, Maharashtra". He works as Head, Department of Zoology and his special interest is entomology.

T.H.SHAIKH presently works as a lecturer in Biology and is interested in entomology. V.D. Deshrande was Head, P.G. Department of Zoology and is currently involved in entomology.

Author Contribution: All three authors have contributed equally to the study of gall midges and in writing this paper.

Acknowledgements: The authors are thankful to Head, P.G. Department of Zoology and Principal, Science College, Nanded for providing laboratory facilities.

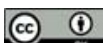

OPEN ACCESS | FREE DOWNLOAD
Abstract: Three new species of gall midge, namely Anarete bharatisp. nov., A. basmatensis sp. nov., and $A$. longipalpi sp. nov., are described from Maharashtra, India. These three new species can be easily recognized by the presence of: i) the subdorsal plate being incised apically, ii) the terminal lamella of the ovipositor being elongated oval, and iii) the terminal lamella of the ovipositor being oval in shape. A key to the Indian species of the genus is provided.

Keywords: Anarete, Cecidomyiidae, Diptera, Lestremiinae, new species

Abbreviations: Cu - cubitus; M1+2 - Medius 1+2; M1 - Medius 1; M3+4 - Medius 3+4; M2 - Medius 2; R5 - Radius 5.

\section{INTRODUCTION}

The genus Anarete was erected by Haliday (1833). Salient features of this genus are flagellar antennal segments without distinct stems and crenulate whorls, segments with roots extending anteriorly, Pedicel in male strongly enlarged. The genus is known by three Indian species viz. i) A. manii Rao; ii) A. allahabadensis Grover; iii) and A. sitapurensis Grover, Gagné (2004). The types are deposited presently with P.G. Department of Zoology, Science College, Nanded, Maharashtra, India.

\section{Anarete bharati sp. nov.}

(Figs. 1-7)

\section{Material examined}

Holotype: Male, 21.ix.1998, dissected and mounted on slide, labeled on wing, Botanical Garden, Science College Campus, Nanded, Maharashtra, India, coll. S.S. Bhalerao (An-1).

Paratype: 1 male, data same as holotype, dissected and mounted on slide (An-1a).

Etymology

The specific epithet bharati refers to the country of occurrence, Bharat i.e. India.

\section{Diagnostic features}

Male: Body $1.00 \mathrm{~mm}$ long

Head: Eye bridge four facets wide, ocelli two, trophi normal.

Palpus: (Fig.5) Quadriarticulate, long, sparsely setose; first segment (3:2), shortest of all, globose; second segment (6:3) cylindrical, $2 \mathrm{x}$ as long as thick; third segment (7:2), cylindrical, longer and thinner than the second, length $3.50 \mathrm{x}$ its maximum thickness; fourth segment (13:2), cylindrical, longest of all, nearly $7 \mathrm{x}$ as long as thick.

Antenna: $0.7 \mathrm{~mm}$ long, shorter than body, with $2+7$ segments, flagellar segments globose, sparsely hairy, becoming thinner towards apex; scape (Fig. 4a) (2:4), cup shaped; pedicel (Fig. 4b) (7:9), greatly enlarged; third segment (Fig. 6a) (5:6) not confluent with fourth, globose, thicker than long; fourth segment (Fig. 6b) (4:5), globose, shorter than third; fifth segment (Fig. 6c) (4:5), shorter than third; penultimate segment (Fig. 7) (5:3) nearly $1.7 \mathrm{x}$ as long as broad or circular; terminal segment (Fig. 7) (9.4), longest of all, cylindrical, nearly 2 as long as thick;

Thorax: Scutum dark brown.

Wing: (Fig. 2) (33:14), hyaline, $2.3 \mathrm{x}$ as long as broad, microtrichae spread all over wing, vein $R 5$ interrupting and joining costa beyond middle of wing, veins $M 1$ and $M 2$ longer than vein $M 1+2, M 3+4$ distinct, vein $C u$ simple, curved.

Legs: Dark brown, sparsely hairy, metatarsus longer than rest of the tarsal segments combined together. 


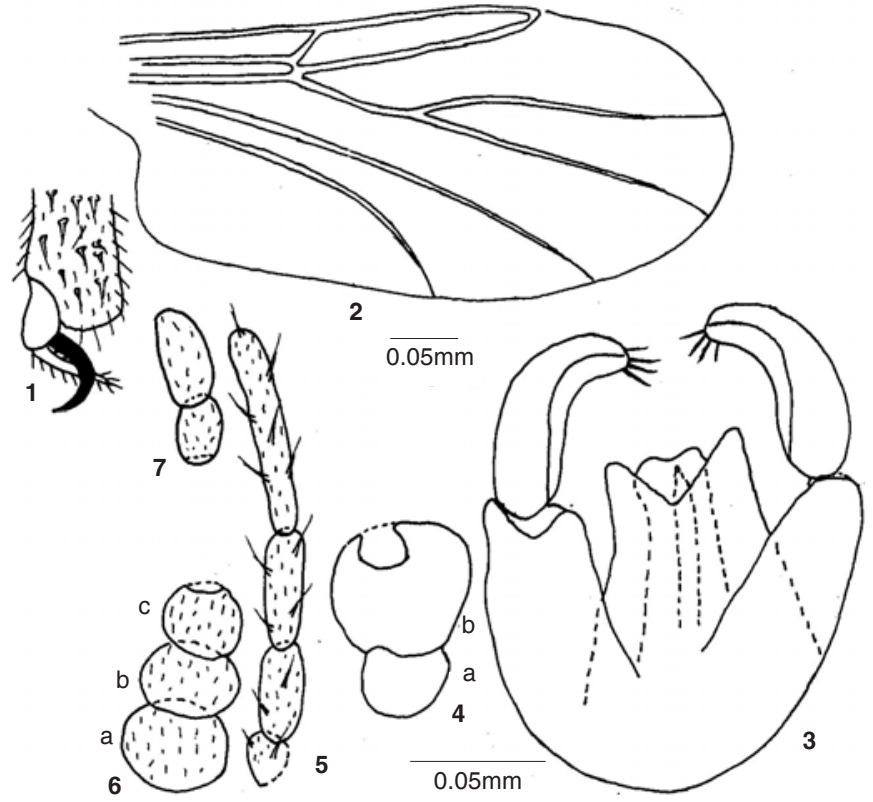

Figures 1-7. Anarete bharati sp. nov. (male)

1 - Claw; 2 - Wing; 3 - Genitalia; 4 - Scape and Pedicle;

5 - Palpus; $6 a, b, c$ - Third, fourth and fifth antennal segments;

7 - Penultimate and terminal antennal segments

Claw: (Fig. 1) (4), dark brown, evenly curved, simple on all legs; empodium (3) $0.75 \mathrm{x}$ as long as claw.

Genitalia: (Fig. 3) Pale brown, sparsely setose; basal clasp segment (16:5) cylindrical, without lobe, 3.2 as long as broad; terminal clasp segment (10:3) cylindrical, curved apically, thicker at base than at apex, ending with a few long chitinised spines, tooth absent; dorsal plate (15:10) longer and broader than subdorsal plate, deeply incised in middle, lobes angular at tips, hairy; subdorsal plate (11:5) shorter than the dorsal, broader at base than at apex, with a shallow incision apically, lobes round; genital rod (10) shorter than subdorsal plate, long, slender.

Female: Unknown.

\section{Remarks}

A. bharati sp. nov. closely resembles $A$. allahabadensis Gorver in its palpal segments and wing venation, but differs from the same in having: i) two ocelli; ii) metatarsus being longer than rest of tarsal segments combined; iii) subdorsal plate being incised apically.

\section{Anarete basmatensis sp. nov.}

(Figs. 8-15)

\section{Material examined}

Holotype: Female, 03.ix.2003, dissected and mounted on slide, labelled, at light, Basmathnagar, Maharashtra, India, coll. S.S. Bhalerao (An-2).

Paratype: 1 female, data same as of holotype. Dissected and mounted on slide (An-2a).

\section{Etymology}

The specific epithet basmatensis refers to the locality Basmatnagar, Maharashtra, India.

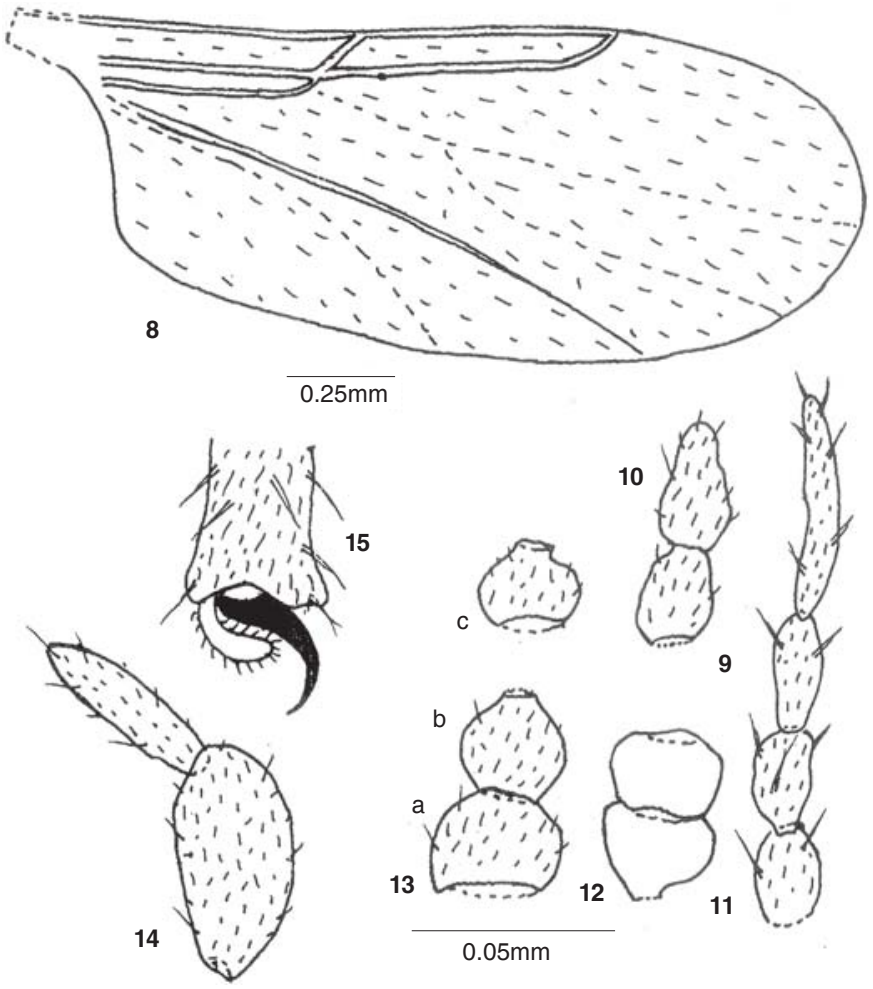

Figures 8-15. Anarete basmatensis sp. nov. (female) 8 - Wing; 9 - Penultimate antennal segment; 10 - Terminal antennal segment; 11 - Palpus; 12 - Scape and pedicel; 13 a,b,c - Third, fourth and fifth antennal segments; 14 - Ovipositor; 15 - Claw

\section{Diagnostic features}

Female: Body $1.6 \mathrm{~mm}$ long, brown in preserved condition;

Head: Ocelli two; eyes not confluent above. Eye bridge two facets wide; Trophi normal.

Palpus: (Fig. 1 1) Quadriarticulate, pale brown, long, sparsely setose; first segment (10:7), subcylindrical, broad medially, length 1.42 its maximum thickness; second segment (10:6), cylindrical, as long as first and $1.66 \mathrm{x}$ as long as thick; third segment (12:5), cylindrical, longer and thinner than second, $2.20 \mathrm{x}$ as long as thick; fourth segment (24:4), cylindrical, longest of all, length $6 \mathrm{x}$ as long as thick.

Antenna: $0.29 \mathrm{~mm}$ long, shorter than body, with $2+8$ segments, segments globose with two whorls of bristles basally, enlargements with sensory bristles above middle of segment, apical stems short; scape (Fig. 12) (8:11), cup shaped, pedicel (Fig. 12) (13:14), subglobose, thicker than long; third segment (Fig. 13a) (9:11), not confluent with fourth, thicker than long; fourth segment (Fig. 13b) (8:10), subglobose, shorter than third and thicker than long; fifth segment (Fig. 13c) (8:9), shorter than fourth, and nearly as long as thick; sixth to eighth segments similar to fifth; penultimate segment (Fig. 9) (9:7), longer and thinner than fifth and $1.21 \mathrm{x}$ as long as thick; terminal segment (Fig. 10) (13:7), longest of all, with a sub apical constriction, length $1.85 \mathrm{x}$ as long as thick, ending with a short knob, length $1.8 \mathrm{x}$ as long as thick.

Thorax: Scutum dark brown, scutellum and postscutellum brown.

Wing: (Fig. 8) (37:15), hyaline, $2.46 \mathrm{x}$ as long as broad, clothed with fine microtrichae, vein $R$ s short, vein $R 5$ joining costa in distal third of wing but not interrupting costa, vein 
$M 1+2$ obsolete, veins $M 3+4$ and $C u$ simple.

Legs: Long, sparsely hairy, metatarsus (33) $2.5 \mathrm{x}$ as long as second segment, and $0.7 \mathrm{x}$ as long as rest of the tarsal segments combined.

Claws: (Fig. 15) (8), dark brown, evenly curved, simple on all legs; empodium (5) $0.6 \mathrm{x}$ as long as claw.

Ovipositor: (Fig. 14) Exerted, lamellate, basal lamella longer and broader than the terminal and the latter elongated oval

Male: Unknown.

\section{Remarks}

Anarete basmatensis sp. nov. comes close to $A$. manii Rao in characters of antenna, palpus and wing, but can be easily distinguished from the latter in having: a) empodium nearly half the length of the claw; b) terminal lamella of the ovipositor elongated oval.

This new species can be separated from $A$. longipalpi sp. nov. by: a) terminal lamella of ovipositor elongated oval in shape; b) metatarsus being shorter than rest of the tarsal segments combined.

\section{Anarete longipalpi sp. nov.}

(Figs. 16-23)

\section{Material examined}

Holotype: Female, 10.ix.1999, dissected and mounted on slide, labelled, at light, Science College Campus, Nanded, Maharashtra, India, coll. S.S. Bhalerao (An-3).

Paratype: One female, collected and mounted on slide, coll. data as of holotype (An-3a).

\section{Etymology}

The specific epithet longipalpi refers to long palpi of the species.

\section{Diagnostic features}

Female: Body $1.33 \mathrm{~mm}$ long, pale brown in preserved condition.

Head: Ocelli absent. Trophi slightly produced.

Palpus: (Fig.16) Quadriarticulate, long, pale brown, sparsely setose; first segment (13.8), subcylindrical, shortest of all, 1.70 $\mathrm{x}$ as long as thick; second segment (15.7), subcylindrical, longer and thinner than first, $2.14 \mathrm{x}$ as long as thick; third segment (14:6) cylindrical, narrow at base, broad apically, nearly as long as second and $2.33 \mathrm{x}$ as long as thick; fourth segment (32:4) cylindrical, longest of all, $8.00 \mathrm{x}$ as long as thick.

Antenna: $0.31 \mathrm{~mm}$ long, shorter than body, with $2+9$ flagellar segments, segments globose, with two whorls of setae at base and sensory processes above middle of segments, without basal stems but with short apical stems; scape (Fig. 19a) (9:8), subglobose; pedicel (Fig. 19b) (10:10), longer and thicker than

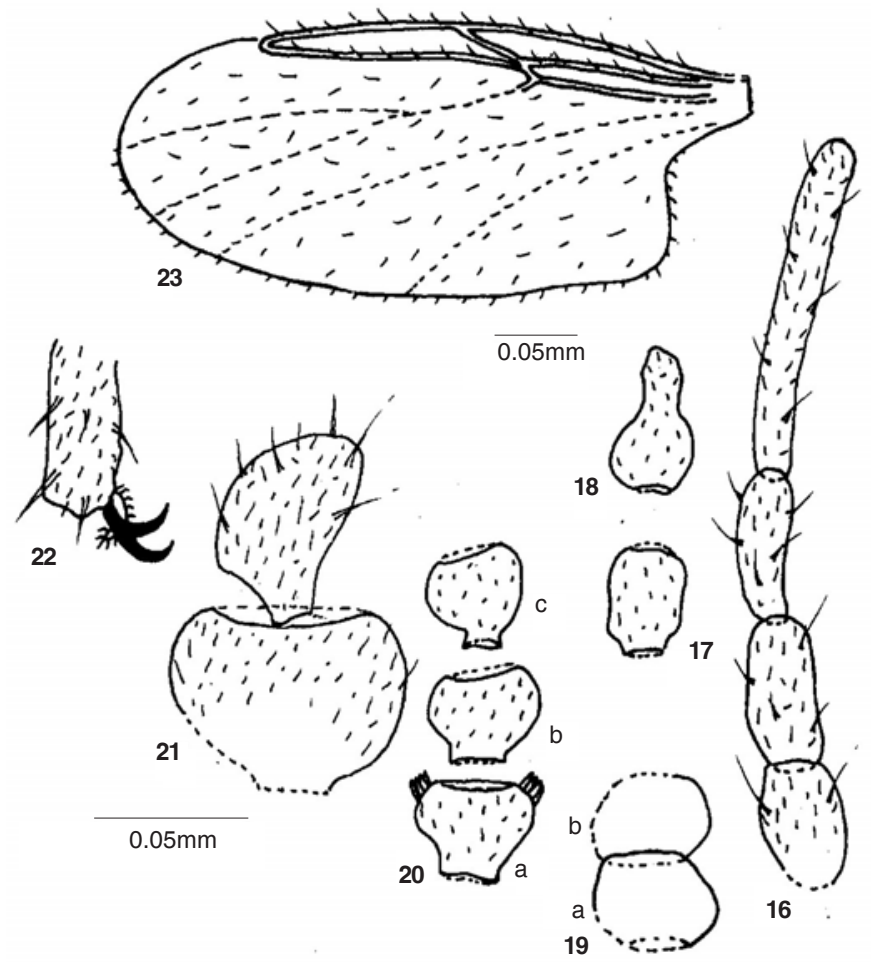

Figures 16-23. Anarete longipalpi sp. nov. (female)

16 - Palpus; 17 - Penultimate antennal segment;

18 - Terminal antennal segment; 19a - Scape, b - Pedicel;

20 - a,b,c - Third, fourth and fifth antennal segments;

21 - Ovipositor; 22 - Claw; 23 - Wing

scape; third segment (Fig. 20a) (9:10), not confluent with fourth, with a short basal prolongation, length of the enlargement 0.90 $\mathrm{x}$ its maximum thickness; fourth segment (Fig. 20b) (7:9), shorter than third, length of the enlargement $0.77 \mathrm{x}$ its maximum thickness; fifth segment (Fig. 20c) (8:9), shorter than third, length of its enlargement $0.9 \mathrm{x}$ its maximum thickness; penultimate segment (Fig.17) (9:7), $1.28 \mathrm{x}$ as long as thick; terminal segment (Fig. 18) (12:7), broad basally, ending with an apical knob, longest of all, 1.84 x as long as thick.

Thorax: Scutum dark brown, scutellum and postscutellum brown.

Wing: (Fig. 23) (40:80), hyaline, nearly rectangular, $2.20 \mathrm{x}$ as long as broad, microtrichae scattered uniformly all over wing, vein R5 uniting costa at distal third of wing and not interrupting at its union; vein $M 1+2$ faint, shorter than veins $M 1$ and $M 2$; veins $M 3+4$ and $\mathrm{Cu}$ obsolete.

Legs: Long, sparsely setose, metatarsus as long as rest of terminal tarsal segments combined, second tarsal segment 0.35 $\mathrm{x}$ as long as metatarsus, third segment shorter than second; terminal tarsal segment longer than fourth.

\section{Key to the males of Indian species of Anarete}

1. Ocelli absent; metatarsus shorter than the terminal tarsal segments combined, subdorsal plate entire ............2 Ocelli two; metatarsus longer than rest of the tarsal segments combined, subdorsal plate incised apically.......

bharati sp. nov

2. Antenna with $2+8$ segments; fifth antennal segment $1.33 \mathrm{x}$ as long as thick; subdorsal plate triangular and longer than the genital rod. allahabadensis Grover, 1970

Antenna with $2+7$ segments; fifth antennal segment as long as thick; subdorsal plate linear and shorter than genital rod. sitapurensis Grover, 1970 
Key to females of Indian species of Anarete Haliday, 1833

1.

Terminal lamella of ovipositor oval

2

Terminal lamella of ovipositor elongated and oval.

2. Metatarsus shorter than terminal tarsal segment combined.

allahabadensis Grover Metatarsus as long as terminal tarsal segment combined longipalpi sp. nov.

3. Metatarsus as long as terminal tarsal segment combined Metatarsus shorter than the terminal tarsal segments combined.

manii Rao basmatensis sp. nov.

Claw: (Fig. 22) (6), stout, dark brown, dentate; empodium (2) less than half the claw.

Ovipositor: (Fig. 21) Exerted, lamellete, basal lobe cup shaped, broad apically, terminal lamella oval and shorter than the basal.

Male: Unknown.

\section{Remarks}

Anarete longipalpi isp. nov. is similar to $A$. allahabadensis Grover in its palpal and antennal segments and wing venation, but can easily be distinguished from the latter in having oval terminal lamella of the ovipositor.

This new species can easily be separated from $A$. basmatensis sp. nov. in having: a) terminal lamella of the ovipositor oval in shape, b) metatarsus being equal to the length of the rest of the tarsal segments combined.

\section{References}

Gange, R.J. (1973). Family: Cecidomyiidae, pp.480-517. In: Delfinado, M.D. and D.E. Hardy (eds.).Catalogue of The Diptera of The Oriental Region 1.

Grover, P. (1970). Studies on gall midges of India XXXIII on a study of Indian Lestremiinae. Cecidologia Indica 5(3): 121-180.

Grover, P. (1975). Studies on gall midges from India XL keys to gall midges of oriental region. Cecidologia Indica 10(1\&2): 1-106.

Mani, M.S. (1934). Studies on Indian Itonidiadae (Cecidomyiidae: Diptera). Records of Indian Museum 36: 381.

Mani, M.S. (1946). Studies on Indian Itonididae (Cecidomyiidae: Diptera) - VIII. Keys to the genera from the oriental region. Indian Journal of Entomology 7(1\&2): 189-235.

Rao, S.N. (1953). Six new species of gall midges (Itonididae: Diptera) from India. Records of Indian Museum 50(3-4): 307-320.

Sharma, R.M. (2003). Anarete orientalis Adwant \& Rao. A checklist of Gall midges (Diptera: cecidomyiidae) from Maharashtra state (Abstract no. E-1 : 79, 5th All India Congress of Zoology, Bhopal). Annals of forestry 11(2): 269-270. 